\title{
Experimental Investigation on Vegetative Oils under Accelerated Thermal Ageing against Their Dielectric Strength
}

\author{
Siti Sufiah Abd Wahid ${ }^{1}$, Mohd Fikri Hilmi Mohd Taib², Yanuar Z. Arief ${ }^{3}$, Mohd Hafizi Ahmad ${ }^{4}$, \\ Noor Azlinda Ahmad ${ }^{5}$, Nor Asiah Muhamad ${ }^{6}, Z_{\text {Zuraimy Adzis }}{ }^{7}$, Mohd Hafiez Izzwan Saad ${ }^{8}$ \\ ${ }^{1}$ Faculty of Electrical Engineering, Universiti Teknologi MARA, 81750 Masai, Johor, Malaysia \\ 2,3,4,5,6,7 Institute of High Voltage \& High Current, Faculty of Electrical Engineering, Univerisiti Teknologi Malaysia \\ (UTM), 81310 Johor Bahru, Malaysia \\ ${ }^{8}$ Faculty of Engineering, Department of Electrical and Electronic Engineering, Universiti Malaysia Sarawak, \\ 94300 Kota Samarahan, Sarawak, Malaysia
}

\section{Article Info}

Article history:

Received Feb 8, 2017

Revised Apr 10, 2017

Accepted Apr 26, 2017

\section{Keyword:}

Accelerated thermal ageing

Dielectric strength

Electrical properties

Vegetative oil

Weibull probability

\begin{abstract}
Insulation is one of the most important parts in high voltage apparatus such as power transformer. Most power transformer use liquid insulation material, known as power transformer oil. Petroleum-based oil so called mineral oil has been used for many years as power transformer oil. This is due to its high dielectric field strength, low dielectric loses and good long-term performance. This research work has been carried out to investigate the effect of thermal accelerated ageing on electrical properties for several vegetative-based oils. The oil samples that have been used in this research work are soy bean-based oil (FR3) and commercial palm-based oil (PFAE). As comparison, Hyrax mineral oil has also been investigated. The results revealed that vegetative-based oils have as well as dielectric strength compared with mineral oil. It was found that the dielectric strength for all oil samples decreased when undergo the thermal accelerated ageing process.
\end{abstract}

Copyright () 2017 Institute of Advanced Engineering and Science. All rights reserved.

\section{Corresponding Author:}

Yanuar Z. Arief,

Institute of High Voltage \& High Current,Faculty of Electrical Engineering,

Universiti Teknologi Malaysia (UTM),

81310 Johor Bahru, Malaysia.

Email: yzarief@fke.utm.my

\section{INTRODUCTION}

Petroleum-based oil so called mineral oil is the common insulating liquids that has been used for centuries due to its high dielectric properties, low viscosity, and inexpensive. However, it lacks in the ability to comply with the environmental and safety laws. Due to these deficiencies concern, and cost considerations on its long term working life span, many researches are being done to replace the use of mineral oil with biodegradable type of insulation oil.

Nowadays, researchers are actively searching for new types of insulating material, which are more environmental friendly. Therefore, this research work has been carried out to investigate the electrical properties and effect of thermal accelerated ageing against the electrical properties for several vegetativebased oils. During real operation, insulating oil is subjected to heat, oxygen and electrical discharge, which may lead to its degradation. Basically, the rate of aging is normally a function of temperature and moisture. Hence, this process is carried out in order to investigate the rate of degradation of the oils.

Many researchers have been investigating on this field [1]-[3]. However, effect of accelerated thermal ageing on vegetative oils is not widely reported. The main objective of research work is to investigate the effect of accelerated thermal ageing on vegetative oils as electrical insulation. 